\title{
Ensino agrícola na formação da infância e adolescência desvalida dos anos de 1930 na Paraíba: O caso de Pindobal
}

Agricultural education in training of helpless childhood and adolescence of the 1930s in Paraíba:

The case of pindobal

La enseñanza agraria en la formación de la niñez y adolescencia vulnerable de los años 1930 en la paraíba: El caso de pindobal

Recebido: 18/06/2021 | Revisado: 24/06/2021 | Aceito: 26/06/2021 | Publicado: 11/07/2021

\author{
Gabriel Alves do Nascimento \\ ORCID: https://orcid.org/0000-0003-0190-9235 \\ Universidade Federal da Paraíba, Brasil \\ E-mail: gabrielalves.educ@gmail.com \\ Charliton José dos Santos Machado \\ ORCID: https://orcid.org/0000-0002-4768-8725 \\ Universidade Federal da Paraíba, Brasil \\ E-mail: charlitonlara@yahoo.com.br
}

\begin{abstract}
Resumo
O presente artigo trata de uma investigação em andamento, sobre a Escola Profissional Presidente João Pessoa (Pindobal) localizada no município de Mamanguape no Estado da Paraíba, fundada em 1930. Esta investigação tratará de abordar o Ensino Agrícola (Mendonça, 2007) como principal ferramenta pedagógica controladora da infância e adolescência masculina desvalida. A abordagem metodológica é qualitativa (Bogdan \& Bikclen, 1999) e a postura analítica utilizada é o Paradigma Indiciário (Ginzburg, 1989) e a Micro-História (Vainfãs, 2002). Os resultados preliminares que encontramos validam Pindobal como uma instituição correcional, destinada a recolher os menores vadios e delinquentes para ministrar um ensino útil para o Estado brasileiro e paraibano. O Estado brasileiro tratou de fundar instituições para dois tipos de Brasil: o Brasil da classe trabalhadora e dos pobres, fundando instituições a exemplo de Pindobal no século XX para imputar o trabalho agrícola como única maneira de salvação dessa população e o Brasil da classe dirigente, que fundou instituição como o Colégio do Caraça destinado aos homens do futuro. Ambas instituições são austeras e trata a questão moralizante em sua centralidade, embora uma destina-se aos pobres e a outra destina-se aos filhos da classe dirigente.
\end{abstract}

Palavras-chave: Ensino agrícola; Escola Profissional Presidente João Pessoa; Pindobal.

\begin{abstract}
This article deals with an ongoing investigation about the Presidente João Pessoa Professional School (Pindobal) located in the municipality of Mamanguape in the State of Paraíba, founded in 1930. This investigation will address Agricultural Education (Mendonça, 2007) as the main pedagogical tool controlling male childhood and adolescence. The methodological approach is qualitative (Bogdan; Bikclen, 1999) and the analytical posture used is the Evidential Paradigm (Ginzburg, 1989) and the Micro-History (Vainfãs, 2002). The preliminary results that we found validate Pindobal as a correctional institution, destined to collect stray and delinquent minors to provide an useful education for the Brazilian and Paraíba State. The Brazilian State tried to found institutions for two types of Brazil: the Brazil of the working class and the poor, founding institutions such as Pindobal in the 20th century to attribute agricultural work as the only way of saving this population and Brazil of the ruling class, who founded an institution such as the Colégio do Caraça for the men of the future. Both institutions are austere and address the moralizing issue in its centrality, although one is aimed at the poor and the other aimed at the children of the ruling class.
\end{abstract}

Keywords: Agricultural education; Presidente João Pessoa Vocational School; Pindobal.

\section{Resumen}

El presente artículo trata de una investigación en curso, sobre la Escuela Profesional Presidente João Pessoa (Pindobal) ubicada en el municipio de Mamanguape en el Estado de Paraíba, fundada en 1930. Esta investigación tratara de exponer la enseñanza agraria (Mendonça, 2007) como principal herramienta pedagógica manipuladora de la niñez y adolescencia masculina vulnerable. El enfoque metodológico es cualitativo (Bogdan; Bikclen, 1999) y la postura analítica utilizada es el Paradigma Indiciario (Ginzburg, 1989) y la Microhistoria (Vainfãs, 2002). Los resultados preliminares que encontramos validan a Pindobal como una institución correccional, destinado a recoger a los menores vagabundos y malhechores para impartir una enseñanza útil para el Estado brasileño y paraibano. El Estado brasileño se ha encargado de fundar instituciones para dos tipos de Brasil: El Brasil de la clase trabajadora y de 
los pobres, fundando instituciones a ejemplo de Pindobal en el siglo XX para asignar el trabajo agrario como única manera de salvar a esta población y el Brasil de la clase dirigente, que ha fundado institución como el Colégio do Caraça destinado a los hombres del futuro. Ambas instituciones son austeras y trata la cuestión moralizante en su centralidad, aunque una está destinada a los pobres y la otra a los hijos de la clase dirigente.

Palabra clave: Enseñanza agraria; Escuela Profesional Presidente João Pessoa; Pindobal.

\section{Introdução}

Este artigo é fruto de inúmeras inquietações gestadas na disciplina de Tópicos Especiais em História Social durante o curso de Mestrado em Educação (PPGE), na linha de pesquisa em História da Educação na Universidade Federal da Paraíba (UFPB). É um recorte da dissertação em andamento, intitulada: A educação moral na formação da infância e adolescência desvalida moderna: o caso de Pindobal na Paraíba do século XX. Nosso objetivo é o de discutir acerca do Ensino Agrícola relacionado aos conceitos de infância e adolescência desvalida, utilizando Pindobal, em meados do ano de 1930.

Não utilizaremos o termo menor ao abordar os sujeitos encaminhados a Pindobal, termo amplamente difundido nas políticas assistenciais das primeiras décadas do século XX e intensificado com o Código de Mello Matos - Código do Menor de 1937 -, trabalharemos com os termos: infância e adolescência, pois abrangem as especificidades desses sujeitos, de modo a respeitar a sua história como sujeitos de direitos que foram estigmatizados, durante o século XX, como menores infratores e menores de idade. Nosso intuito é problematizar a relação desses sujeitos com as políticas assistenciais do Estado brasileiro, compreendendo que a utilização do termo menor reforça estereótipos historicamente construídos com o objetivo de marginalizar essa população (Rizzini \& Celestino, 2016).

Pindobal possuiu vários nomes em meados de 1930, sendo eles: Aprendizado Agrícola; Centro Agrícola e Escola Profissional Presidente João Pessoa. É uma instituição paraibana criada nos anos de 1930, conhecida por seus métodos austeros de ensino profissionalizante agrícola, com o intuito de formar a infância e adolescência pobre, dando-lhes um ensino útil (Costa, 1941). Pindobal é um local destinado às crianças e aos adolescentes do sexo masculino em situação de vulnerabilidade social, filhos da classe trabalhadora, sujeitos que, muitas vezes, estariam nas ruas trabalhando ou cometendo pequenos atos infracionais (Santos, 2004).

Esses sujeitos são concebidos, durante o início do século XX, como potenciais criminosos, como podemos verificar nas políticas de assistência social à infância e adolescência pobre em meados dos anos de 1930 (Rizzini, 2011). Pindobal seria essa espécie de instituição controladora que acolheria esses sujeitos, destinada a recolhê-los e a ministrar um ensino útil capaz de modificar a sua situação de rua. O imaginário social concebido sobre Pindobal é de que ela seria uma espécie de masmorra ameaçadora, e o medo passaria a transitar o imaginário social em três momentos: 1) A possibilidade de ir para a instituição; 2) O momento em que os sujeitos são encaminhados e adaptados a suas regras; e 3) A sua permanência e a possibilidade da fuga.

Esses três momentos são forjados pelo sentimento de medo, o medo do desconhecido, de ir para a temível Pindobal, capaz de moldar e consertar os desviados e anormais. Este é um discurso muito comum na Medicina e na Psicologia nas primeiras décadas do século XX, mas que, em meados de 1930, está presente em outros campos do conhecimento, como "[...] no campo da educação, no controle da imigração, no campo do direito, do trabalho, na identificação da população civil [...]" (Corrêa, 2016, p.145). As políticas para a infância e adolescência desvalida do Estado brasileiro, nos anos de 1930, estão quase sempre voltadas para a correção de desvios e a prevenção de crimes, pois "[...] as políticas propostas para o cuidado da criança abandonada estão quase sempre ausentes [...]" (Corrêa, 2016, p.145).

Nesse cenário, a problemática que tratamos neste artigo é de que: Pindobal é uma instituição atravessada pelo simbolismo de ser escola e de ser prisão, na qual verificamos que o Ensino Agrícola é o principal instrumento pedagógico para o controle da infância e adolescência em situação de vulnerabilidade social, nessa direção, o trabalho destinado a esses sujeitos está relacionado a um pensamento nacionalista para o progresso, utilizando o trabalho profissional agrícola como principal 
instrumento de superação da sua condição de desvalido e anormal, passando a ser um sujeito produtivo, eficiente e, então, adequado a viver na sociedade capitalista.

Partindo da problemática, encaminhamos os aspectos metodológicos que percorremos para a consolidação desta investigação. Nossa pesquisa é documental de base qualitativa (Bogdan \& Biklen, 1999), em que as fontes utilizadas são os textos impressos (Barbosa, 2007), publicados em alguns jornais, coletados no Instituto Histórico e Geográfico da Paraíba (IHGP) e na Biblioteca Nacional Digital (BNDIGITAL). A perspectiva historiográfica analítica em que ancoramos a nossa pesquisa é a do Paradigma Indiciário (Ginzburg, 1989) e da Micro História (Vainfas, 2002; Levi, 1992).

Utilizaremos, neste trabalho, a redução de escala proposta pela Micro História, ao visualizar a experiência de uma instituição local - Pindobal - a partir de alguns textos impressos, entendendo que, “[...] a pesquisa histórica não é uma atividade puramente retórica e estética [...]" (Levi, 1992, p.135). O nosso empenho se dá em perceber as conflituosas tramas existentes sobre instituições como a de Pindobal, desenvolvendo os contornos para uma história vista sob a ótica da infância e adolescência desvalida, com o compromisso de articular uma experiência local com concepções altamente operantes, a exemplo do Ensino Agrícola, para explicitar por meio de quais condições Pindobal é criada e exerce seu papel na sociedade paraibana.

Portanto, socialmente, Pindobal é tratada como instituição que receberia aqueles que não se comportassem e não obedecessem a seus pais e às regras do Estado brasileiro. Entre o imaginário social e as práticas concretas verificadas nos textos impressos, existem uma lacuna que este trabalho tratará de abordar. Acreditamos que este artigo poderá servir de ponto de partida ou de chegada para pesquisadores e pesquisadoras da História Social da Infância, da História do Ensino Agrícola e da História das Instituições Profissionais Paraibanas no século XX.

\section{Metodologia}

A investigação que desenvolvemos vincula-se aos desafios e problemáticas da História da Educação. É uma pesquisa de continuidade em desenvolvimento no Mestrado acadêmico do Programa de Pós-Graduação em Educação da Universidade Federal da Paraíba e surge a partir de inquietações germinadas durante a graduação em Pedagogia com área de aprofundamento em Educação do Campo e do Programa Institucional de Bolsas de Iniciação Científica (PIBIC: 2016-2019). Os caminhos metodológicos que percorremos empreendem-se na coleta, identificação, comparação e análise dos dados documentais e iconográficos, tomando como referência o Paradigma Indiciário (Ginzburg, 1989). Dessa maneira, almejamos visualizar de forma singular a história e a memória de uma instituição específica, acreditando que, ao desvelar as práticas e as representações desta instituição, iremos corroborar para apresentar a narrativa da sociedade paraibana a partir da terceira década do século XX e, objetivamente, visualizar o discurso acerca da juventude pobre, daqueles sujeitos que são encaminhados a Pindobal. A utilização da pesquisa qualitativa está relacionada ao que Flick (2009) aponta como sendo a pluralização das esferas da vida, pois,

A pesquisa qualitativa é de particular relevância ao estudo das relações sociais devido à pluralização das esferas da vida. [...] e a dissolução de "velhas" desigualdades sociais dentro da nova diversidade de ambientes, subculturas, estilos e formas de vida. Essa pluralização exige uma nova sensibilidade para o estudo empírico das questões. [...] Dessa forma, a pesquisa está cada vez mais obrigada a utilizar-se das estratégias indutivas. Em vez de partir de teorias e testá-las, são necessários "conceitos sensibilizantes" para a abordagem dos contextos sociais a serem estudados". (Flick, 2009, p21).

Partido deste cenário, este artigo não poderia adotar outra abordagem se não a qualitativa, pois é partindo da centralidade de conceitos como: Educação Rural e Infância e Adolescencia Desvalida que vamos ao encontro de uma instituição local, intitulada: Pindobal, visualizando de maneira empírica os preâmbulos desta instituição ao instituir a Educação 
Rural como principal ferramenta pedagógica para o controle da Infância e da Adolescencia Desvalida na Paraíba nos anos de 1930.

Os acervos nos quais desenvolvemos nossa busca são: a Biblioteca Nacional Digital (BNDigital); o Arquivo Nacional (AN); o Instituto Histórico e Geográfico da Paraíba (IHGP); a Fundação Casa de José Américo (FCJA); o Arquivo da Assembleia Legislativa da Paraíba (Casa de Epitácio Pessoa); o Arquivo Histórico da Fundação Espaço Cultural (FUNESC). A partir da catalogação e análise do texto impresso, durante a construção da Monografia intitulada: Histórias e Memórias de Pindobal (1930-1950): As Crianças "Indesejáveis", foi identificado que Pindobal é caracterizada como instituição regeneradora, destinada a ensinar e a corrigir os menores transviados da sociedade paraibana, versando entre o ensino profissional agrícola para o trabalho e as práticas correcionais para o civismo. Partindo deste indício, construímos a investigação monográfica, cujo o recorte do Ensino Agrícola é abordado no presente artigo.

\section{Ensino Agrícola Brasileiro: Pindobal e a Formação dos "Improdutivos"}

O Ensino Agrícola possui a intenção de formar a infância e adolescência masculina desvalida paraibana para o trabalho profissional agrícola redentor, capaz de transformar as suas vidas, tornando-os cidadãos produtivos e, consequentemente, ressocializados. A preocupação do Brasil nas primeiras décadas do século XX é com a diminuição dos crimes cometidos por esses sujeitos, e, principalmente, com o combate ao ócio e à vadiagem, vistos como principais males da falta de progresso em um Brasil que precisava se modernizar e moralizar-se.

Nos últimos anos do século XIX e nas primeiras décadas do século XX, a ação pedagógica dos setores dominantes, ao lado de outras práticas mais diretamente repressivas, estará voltada para a "reconstrução nacional", a conformação da cidadania, e para a questão da organização do trabalho. São desenvolvidas inúmeras estratégias e dispositivos visando a moralização e o ajustamento do trabalhador à nova ordem social. (Moraes, 2000, p.70).

Pindobal é uma instituição paraibana cuja finalidade é a de aplicar o Ensino Agrícola, formando a infância e a adolescência desvalida paraibana através de um ensino útil e redentor. A sua inclinação é, no mínimo, curiosa. Os impressos destacam que tal instituição é destinada a recolher das ruas aqueles sujeitos abandonados e delinquentes. A saber,

O aprendizado agrícola que o governo do Estado vae instalar na fazenda Pindobal, em Mamanguape, será dirigido pelo professor Sizenando Costa. Destina-se a recolher não só os menores abandonados como os delinquentes, afim de ministrar-lhes conhecimentos práticos de agricultura geral e industriais, podendo o tirocínio destas últimas ser feito na fábrica de Rio Tinto. O objetivo da fundação em apreço será preparar lavradores, encaminhando para a profissão manufactureira os menores que revelarsem para a mesma uma inclinação especial. O governo cogita também em fixar em Pindobal um pequeno núcleo de colonização alemã, a começar com o estabelecimento de doze famílias. (O Aprendizado..., 1930).

Neste trecho, percebemos a problemática vivenciada pelo Brasil dos anos de 1930. Tal instituição está atravessada pela necessidade de conter potenciais criminosos aplicando uma força que seria socialmente inquestionável: O Ensino Técnico e o Trabalho como elementos fundantes e interdependentes para a ressocialização dessa população. Aqui, pretendemos narrar e questionar os contornos dessa instituição de maneira crítica, pensando seus objetivos conectados à concepção de Estado Agrícola, suas influências externas e sua aplicabilidade na sociedade brasileira.

Os Brasis contidos no período pesquisado apresentam-nos uma realidade conflituosa e desigual: o Brasil rural e o Brasil urbano possuem contrastes significativos que nos ajudarão a pensar sobre quais condições instituições como Pindobal foram criadas. Inicialmente, é preciso destacar que a sombra do Brasil escravocrata continua aparente no século XX, que o ensino agrícola tem sua influência na primeira república brasileira, como afirma Mendonça (2007), 
A origem dessa precoce interferência estatal junto à agricultura relaciona-se à abolição da escravidão, marco importante no lento processo de construção das relações de produção capitalistas no campo brasileiro, mediante a redefinição de formas de trabalho compulsório, dando origem a uma indissolúvel e contraditória aliança entre grandes proprietários rurais e a Sociedade Política. [...] (p.246).

Não podemos deixar de notar, apesar de não constar neste artigo, mas precisamos fazer um adendo de que nas imagens - fotografias - encontradas sobre os sujeitos encaminhados a Pindobal, o traço forte da cor, são jovens pretos e majoritariamente são os filhos dos trabalhadores que estão sendo encarcerados em Pindobal, e precisamos ter a consciência de que,

Analisar a transformação das relações sociais e econômicas experimentadas em mais de trezentos anos de escravidão em relações pretensamente livres, sem considerar a cor das pessoas que viveram esse longo e conflituoso processo histórico, nos afasta das reflexões que essa transformação engendra e exige. [...] (Nascimento, 2016, p.609).

A influência do Brasil agrário da primeira república está calcada em práticas de arregimentação de mão-de-obra rural (MENDONÇA, 2007), com o intuito de prover o trabalhador nacional e a criação das entidades patronais agrárias para o ensino agrícola, surgem como alternativa a uma “[...] crise da agricultura destinada a dar conta, segundo a origem de seus enunciantes, de situações regionais específicas [...] Sociedade Paulista de Agricultura/Sociedade Rural Brasileira (paulistas) e a Sociedade Nacional de Agricultura (fluminense).” (Mendonça, 2007, p.245-246, grifos da autora).

Essas agremiações começam a traduzir a vontade latifundiária brasileira em políticas públicas para o setor econômico, destinando uma política para os filhos dos trabalhadores,

Em certas circunstâncias, entretanto, as instituições de "Ensino Agrícola" do Ministério funcionaram como instrumentos de intervenção junto a categorias sociais pouco vinculadas à agricultura, servindo como paliativo à questão social urbana. Este seria o caso dos Patronatos Agrícolas (PAs), criados em 1918 em resposta à conjuntura gerada pela Primeira Guerra Mundial. Rurais por necessidade e agrícolas mais por conveniência do que por vocação já que o trabalho no campo era visto como único meio de preservar sua autosubsistência e manutenção - os Patronatos abrigariam a infância órfã desvalida da cidade do Rio de Janeiro, atendendo a interesses de segmentos urbanoindustriais empenhados em construir uma imagem "profilática" da Capital Federal. Associando as noções de ensino prático e de defesa militar, a lei que criava os Patronatos deixava claro seu escopo, malgrado a retórica filantrópica que os justificava: consistiam numa alternativa às instituições prisionais urbanas, tidas como degradantes e infames. Entretanto, os PAs produziriam um outro tipo de "detentos", terapeuticamente disciplinados por essas escolas de trabalho que "serviam de freio às tendências anárquicas intoleráveis" atribuídas ao novo ator social do período, o proletariado. (Mendonça, 2007, p.248, grifos da autora).

Podemos inferir que Pindobal seria um Patronato Agrícola, a partir das características imprimidas por Mendonça (2007), embora os impressos não digam com clareza que são, mas que em sua configuração de funcionamento possuem todos os elementos destacados pela autora. Sizenando Costa, nomeado primeiro diretor de Pindobal, em sua obra A Escola Rural, destaca,

Visando fixar o homem ao solo, êle trata em seu trabalho sobre as possibilidades e a necessidade de possuir a "Escola Rural", seções de Agricultura, Criação e Pequenas Indústrias, Estas atividades, tão úteis às populações rurais, são realizadas insensivelmente pelas crianças que, por sua vez, as transmitem aos pais e amigos - Maria do Carmo Ramos Pinto Ribeiro, Diretora da Escola Rural Alberto Tôrres, de Recife. (Costa, 1941, p.08).

Este intelectual paraibano assumiu a direção de Pindobal um local privilegiado para a experimentação de suas ideias, de organizar uma instituição voltada para o ensino agrícola, concebendo uma escola menos "livresca" como afirma o próprio autor em sua obra. Percebemos que o discurso de Costa (1941) se mistura ao discurso do movimento escolanovista, ele justifica a necessidade do Estado brasileiro investir na escola agrícola por dois motivos: 1) A possibilidade de promover um 
ensino voltado para o trabalho, que fosse menos livresco e mais prático; 2) Este ensino agrícola estaria relacionado a vocação do nordeste de ser um local agroexportador por natureza e, portanto, o Estado teria gastos ínfimos e o desenvolvimento regional através das atividades agrícolas se sobressairiam.

As políticas de controle destinadas aos filhos dos trabalhadores estão estritamente relacionadas com a criação de instituições moralizantes, a exemplo de Pindobal, que utiliza como principal ferramenta pedagógica o trabalho. Segundo afirma Moraes (2000),

Os setores dirigentes sempre demonstraram apreensão com o crescente número de crianças desamparadas, habitantes das ruas da cidade. Para elas providenciou asilos e reformatórios, instituições moralizadoras, onde o trabalho se constituía em importante recurso pedagógico. (p.73).

A criação dessas instituições é uma resposta de um “[...] país de tradição escravocrata [...]”. (Passetti, 2004, p.354). As desigualdades abissais entre a população brasileira, na configuração dos setores da classe dominante em contraposição com a classe trabalhadora, são marcadas pela usurpação, pela fome e pela falta de políticas públicas que solucionem o problema da miséria nas primeiras décadas do século XX. Discutir sobre trabalho e escola, instituições constituídas a partir dos anseios do Estado brasileiro, é demarcar sobre quais condições a criança e o adolescente pobre são concebidos pelo próprio Estado, pois “[...] uma das maiores 'tarefas' do Estado consiste, justamente, em produzir e impor, sobretudo através da instituição escolar, certas noções e categorias que utilizamos espontaneamente em nosso cotidiano [...].” (Mendonça, 1996, p.1, grifos da autora).

No caso de Pindobal, a força que o Estado aparentemente exercia é a de encarcerar, retirando das ruas, dos olhos da sociedade, aqueles sujeitos vistos como perigosos, imorais, transviados, justificando a sua redenção através da força do trabalho. (Nascimento, Machado \& Almeida, 2021). Entre a ideia e a sua execução, estará a humanidade dos sujeitos encaminhados a Pindobal, suas vontades, seus medos, suas angústias, sua concepção de mundo e seus sonhos. A imprensa é um importante campo investigativo, é através dela que podemos perceber o tom narrativo conferido a Pindobal e aos sujeitos encaminhados,

O saudoso presidente João Pessoa, ao assumir o governo da Parahyba, atentou no problema da vadiagem infantil e dele fez um dos pontos do seu largo, generoso e profícuo programa de governo, creando logo o Centro Agrícola de Pindobal, em Mamanguape, para educação dos menores abandonados. O estabelecimento vem prestando excelentes serviços à sociedade, tornando elementos úteis menores transviados que, sem o amparo e a educação que ali recebem, resvalariam para a delinquência, para a senda do crime. Ali recebem, os jovens brasileiros recolhidos, a par da educação moral, cívica e profissional, instrucção militar e aulas de letras. O Sr. Antenor Navarro, actual interventor federal na Parahyba, mudou o nome da colônia de menores para Centro Agrícola Presidente João Pessoa, prestando assim uma homenagem justíssima à memória do seu fundador. (A Noite, 1931).

Nesse trecho é evidente que o problema não seria a ausência de educação para a infância e a adolescência pobre, não seria a ausência de trabalho digno para seus pais, não seria o problema do abandono infantil, mas o principal problema seria: Vadiagem infantil. A questão da vadiagem para o judiciário brasileiro é um ponto fulcral que conecta o século XX ao brasil escravocrata, nas primeiras quatro décadas do século XX,

O Decreto no 145 de 1893 autorizava o Governo a fundar uma colonia correccional na Fazenda da Boa Vista, existente na Parahyba do Sul (hoje município do Estado do Rio de Janeiro), "ou onde melhor lhe parecer".9 Tal decreto, nos parágrafos de seu artigo $2^{\circ}$, trazia uma definição de vadio: $\$ 1^{\circ}$ Os individuos de qualquer sexo e qualquer idade que, não estando sujeitos ao poder paterno ou sob a direcção de tutores ou curadores, sem meios de subsistencia, por fortuna propria, ou profissão, arte, officio, occupação legal e honesta em que ganhem a vida, vagarem pela cidade na ociosidade. (Prando, 2014, p.4-5) 
O Texto de Prando ao abordar o Decreto de n 145 de 1893 ao autorizar o governo a fundar uma colônia correcional, especificamente onde é hoje o Rio de Janeiro, deixa claro sobre quais ordens e quais estatutos as instituições organizadas nos moldes de Pindobal são fundadas. Essa é uma política liberal de punir os vadios com o afastamento deles do convívio social, o Estado não está preocupado em desenvolver um convívio harmônico entre o sujeito em situação de vulnerabilidade social e a sociedade.

Nesse processo reside, a nosso ver, a mais profunda e estrutural modalidade de violência perpetrada pelo Estado: a violência simbólica, cujo modus operandi se dá à sombra da permanente naturalização de seus objetos e/ou alvos, configurando o que se poderia chamar de um permanente "estado de violência". Onde o que está em jogo não é a integridade física de indivíduos e/ou grupos, mais sim a integridade de sua participação cultural. (Mendonça, 1996, p.2, grifos da autora).

Ou seja, o rótulo de Vadio é imprimido nos sujeitos encaminhados para Pindobal como forma de justificar a sua permanência na instituição. Esse Estado controlador, propulsor de uma desigualdade gigantesca entre as classes sociais brasileiras, tratou de forjar uma infância e adolescência transgressora, desprovida da condição de sujeito de direitos. Ou seja, incapaz de organizar estratégias de superação de sua condição de pobreza e, em resposta a essas estratégias, o Estado trata-os a partir de uma política de segurança nacional. Como afirma Passetti (2004),

Fechavam-se os trinta primeiros anos da República com um investimento na criança pobre vista como criança potencialmente abandonada e perigosa, a ser atendida pelo Estado. Integrá-la ao mercado de trabalho significava tirála da vida delinquencial [...] e educá-la com o intuito de incutir-lhe a obediência. (p.355).

O ensino agrícola desenvolvido por Pindobal é destinado a uma classe: os filhos dos trabalhadores pobres, aqueles que seriam responsáveis por conduzir o trabalho nacional obedecendo às regras da elite dirigente. Evidenciamos dois tipos de instituições criadas para públicos diferentes, enquanto Pindobal desenvolve o trabalho rudimentar agrícola, um trabalho manual visivelmente estigmatizado e desvalorizado no Brasil dos anos de 1930 (Mendonça, 1930), outras instituições, a exemplo do Colégio do Caraça, no período oitocentista, tem a função de formar a elite dirigente, aqueles que seriam responsáveis por guiar e dirigir as vontades da nação (Andrade, 2000).

O ensino técnico agrícola é gradualmente implementado no Brasil, através de políticas desenvolvidas pelo Ministério da Agricultura e o Ministério da Educação e da Saúde, em meados de 1930,

Se é fato que, no decorrer de todo o século XX, a educação brasileira passou por grandes reformulações, complexificando-se proporcionalmente às próprias alterações no padrão de acumulação capitalista, por outro lado, seu cunho dual se manteve enquanto característica basilar. Em meio a este quadro adquire relevância a reflexão acerca do Ensino Agrícola, uma das mais cabais expressões deste dualismo, sobretudo pelo fato de ter sido, ao menos até 1961, atravessado [...] não apenas pela dualidade que antagoniza trabalho manual versus trabalho "intelectual" como também por aquela que polarizou duas agências da Sociedade Política dele encarregadas: o Ministério da Agricultura e o da Educação e Saúde, particularmente nas décadas de 1930 a 1950. (Mendonça, 2007, p.244).

Os sinuosos conflitos do século XX e, em especial nos anos de 1930 estão presentes na Educação a partir dessa dualidade, entre um ensino destinado aos filhos dos trabalhadores pobres e o ensino para os filhos da elite dirigente. O Ensino Agrícola passa a ser o mantra da sociedade capitalista paraibana, como um dos principais instrumentos de ressocialização aos sujeitos internos em Pindobal, essa tática do Estado toma corpo com as políticas implementadas pela pasta da educação aqui na Paraíba e o debate travado pela imprensa é um importante campo de observação daquilo que estava sendo implementado pelo governo estadual. 
Portanto, o Ensino Agrícola está longe de ser um elemento isento das regulações políticas e econômicas da sociedade paraibana, essa modalidade de ensino está a serviço de uma parcela da população, daqueles que enxergam nesse mecanismo uma possibilidade de conter a criminalidade cometida pelas crianças e pelos adolescentes, tratando-a como política de segurança nacional e principalmente fortalecendo os mecanismos de repressão do estado. O Ensino Agrícola mescla dois importantes elementos para o capitalismo: o Ensino e o Trabalho como dois campos interdependentes com o intuito de formar sujeitos propensos a aceitação do trabalho agrícola como única escapatória de sua condição.

\section{O Caso de Pindobal: Infância e Adolescência Desvalida}

Cabe-nos destacar que o sistema assistencial no Brasil se inspirava em modelos assistenciais europeus, ainda que de uma forma mais rudimentar, uma assistência à infância em um mundo colonial, com instituições pensadas para o trabalho físico e compulsório. Segundo Santos (2004, p.213-214), o "[...] aumento da ocorrência de crimes é acompanhado pelo aumento e especialização dos mecanismos de repressão, gerando uma maior incidência de conflitos urbanos, numa clara manifestação do agravamento das tensões sociais".

O elemento da migração para os centros urbanos é outro fator explicativo para a constituição de concepções de ensino agrícola voltados para a classe trabalhadora. É preciso verificar sobre quais condições as políticas de incentivo à indústria e à agroindústria estão sendo implementadas em 1930, quem são os setores beneficiados cujo intuito é o de manter o privilégio de suas demandas,

É dessa inter-relação entre sociedade civil e sociedade política que se teriam originado, da perspectiva teórica adotada, determinadas políticas agrícolas e não outras, privilegiando um setor em detrimento de outro, segundo a correlação de forças política específica. (Mendonça, 2013, p. 4-5).

Deixando de lado a dicotomia entre Estado Urbano e Estado Rural e suas respectivas políticas econômicas e sociais, Mendonça (2013) afirma que a migração de parte da população rural para as cidades não obedeceu a uma regra sistêmica, a partir de uma perspectiva de desvalorização completa dos setores agrários, mas esteve presente em um processo sequenciado de beneficiamento de determinados setores em detrimento de outros. A questão da migração do campo para os centros urbanos não está condicionada a um feito específico, a uma ausência só, mas está direcionada fortemente à concepção de Estado Moderno e que esse Estado se fazia presente nos centros urbanos.

Permanecer no campo seria sinônimo de atraso, e essa concepção se justificaria pela crescente investida de setores agroindustriais em busca do esvaziamento, sendo uma das principais causas do deslocamento dessas populações. Aqui, nosso intuito é verificar os contornos de uma instituição específica, cuja centralidade de seu processo de ensino se faz com o Ensino Agrícola, destinado a atender uma população: As crianças e os adolescentes desvalidos, sujeitos que em situações extremas de negação de direitos que estariam cometendo crimes nos centros urbanos, embora as estatísticas apontam que esses crimes seriam de menor poder ofensivo,

A natureza dos crimes cometidos por menores era muito diversa daqueles cometidos por adultos, de modo que entre 1904 e 1906, 40\% das prisões de menores foram motivadas por "desordens", 20\% por "vadiagem", 17\% por embriaguez e $16 \%$ por furto ou roubo. Se comparados com os índices da criminalidade adulta teremos: $93,1 \%$ dos homicídios foram cometidos por adultos, e somente $6,9 \%$ por menores, indicando a diversidade do tipo de atividades ilícitas entre ambas as faixas etárias. As estatísticas mostram que os menores eram responsáveis neste período por $22 \%$ das desordens, $22 \%$ das vadiagens, $26 \%$ da "gatunagem", $27 \%$ dos furtos e roubos, $20 \%$ dos defloramentos e $15 \%$ dos ferimentos. (Santos, 2004, p.214, grifos do autor). 
Especificamente no caso paraibano, Pindobal estava localizada no campo, no município de Mamanguape. Essa característica poderia estar relacionada a diminuições de fugas, tendo em vista a sua localização geográfica, ao afastamento da instituição dos centros urbanos, com o intuito de manter a distância entre a sociedade produtiva e os improdutivos que precisariam de uma redenção. Assim,

O aprendizado agrícola que o governo do Estado vae instalar na fazenda Pindobal, em Mamanguape, será dirigido pelo professor Sizenando Costa. Destina-se a recolher não só os menores abandonados como os delinquentes, afim de ministrar-lhes conhecimentos práticos de agricultura geral e industriais, podendo o tirocínio destas últimas ser feito na fábrica de Rio Tinto. O objetivo da fundação em apreço será preparar lavradores, encaminhando para a profissão manufactureira os menores que revelarsem para a mesma uma inclinação especial. O governo cogita também em fixar em Pindobal um pequeno núcleo de colonização alemã, a começar com o estabelecimento de doze famílias. (Pelos..., 1930).

Não sabemos ao certo os motivos pelos quais essa instituição se instalou em Mamanguape, podemos inferir que a sua vocação agrícola de produção haveria de ser o principal motivo de sua instalação, pois "[...] o centro educa actualmente cerca de trezentos menores, que praticam o plantio e o trabalho de toda espécie de produtos, notadamente os que são typicos da região [...] (Uma bella..., 1931, p.5).

Como podemos verificar, essa instituição é dirigida por Sizenando Costa, um dos principais articuladores do Ensino Agrícola na Paraíba, em meados dos anos de 1930 a 1940. Costa é um crítico ferrenho ao ensino tradicional, que ele intitula de ensino livresco, como podemos perceber nessa passagem de sua obra A Escola Rural (1941), ao afirmar que os alunos precisam de "[...] aulas vivas, vibrantes, cheias de calor e, acima de tudo, norteadas para formar uma nacionalidade forte, ambiciosa e concisa do seu próprio valor [...]". (Costa, 1941, p.13).

Nesse trecho, o termo nacionalidade é colocado em pauta; Costa tem, em seu pensamento, a necessidade de direcionar um ensino capaz de formar uma nacionalidade forte, sua fala carrega, de modo simbólico e prático, a intenção de instituições como a de Pindobal, capaz de mobilizar o trabalho como centralidade pedagógica. Em outro trecho, Costa (1941) afirma que,

A escola somente de letras, hierática, dogmática; escola, algo de claustro, algo de caserna, deve ceder lugar a uma outra talvez menos palavrosa, menos livresca, e mais dinâmica, mais apropriada ao ambiente e às supremas necessidades coletivas. (p.15).

As supremas necessidades coletivas destacadas por Costa são as necessidades do capital, as necessidades dos setores agrários brasileiros em formar mão-de-obra para o campo. Percebemos que esse personagem possui uma centralidade de ideias que forjaram o pensamento paraibano em busca da perspectiva da Escola Rural e do Ensino Agrícola. A crítica de Sizenando Costa incorpora elementos do Escolanovismo, ou seja, “[...] Pindobal aproxima-se de uma concepção escolanovista, de maneira distorcida, mas que conserva elementos fundantes, como a educação para o trabalho e o desprezo às chamadas aulas de letras [...]. (Nascimento, Machado \& Almeida, 2020, p. 12).

Não é por mera coincidência que Sizenando Costa é nomeado para ser o primeiro diretor de Pindobal, responsável por aplicar e desenvolver trabalhos de toda espécie, "[...] Há ofícinas para preparar mecânicos, sapateiros, carpinteiros e vários outros officios, além de instrucção adequada a ánormaes." (A Parahyba..., 1936, p.1). O diretor implementa, nessa instituição, as ideias de uma instituição de Ensino Agrícola, cuja centralidade pedagógica é o trabalho.

O ensino agrícola de nível elementar, médio e especial 1 foi implantado no Brasil pelo Ministério da Agricultura (MA), ao longo da década de 1910, quando a conjuntura pósabolicionista tornou premente redefinir as formas de controle/tutela sobre a população rural, agora integrada por ex-escravos e seus descendentes, em pleno processo de formação do mercado de trabalho. Daí surgiram as primeiras instituições dedicadas ao "ensino agrícola", pautadas 
pela fixação a terra de jovens filhos de lavradores e da infância desvalida das cidades, a serem dotados das noções elementares de um saber prático. [...]. (Mendonça, 2016, p. 0).

Pindobal não é uma instituição de fácil tradução, pois, diferente do Colégio do Caraça (ANDRADE, 2000), destinado aos filhos da elite Mineira, pautado por uma educação moral que ao mesmo tempo serviria de sustento para a elite dirigente brasileira, Pindobal se opõe em todos os sentidos, carregando apenas o elemento moralizante em identificação com o Caraça. Nessa perspectiva,

O Colégio do Caraça tem um lugar marcado na história da educação de Minas. Não somente por representar a vertente de uma tradição escolar oitocentista, fundada no ensino humanístico, de cunho monacal, responsável pela formação de várias gerações de bacharéis, mais também pela extensão da memória que legou, construída no coletivo e na história dos grupos e que encontra no corpo de uma oralidade-padrão a afirmação de sua identidade. Referir-se ao Colégio do Caraça é sempre traçar o perfil de um colégio modelo, de disciplina austera e da excelência de seu ensino. (Andrade, 2000, p.11).

As diferenças entre Pindobal e o Caraça são inúmeras, iniciando pelo período, já que o Colégio do Caraça funcionou até 1912, passando por fechamentos e reaberturas, foi dirigido majoritariamente pelos religiosos da Congregação lazarista, com influência portuguesa, francesa e, por fim, brasileira, segundo a periodização de Andrade (2000). Essas diferenças estão sendo postas para pensarmos duas instituições distintas que carregam uma semelhança: o ensino austero e moralizante. Desse modo, é importante acrescentar que o Brasil oitocentista protagonizado pelo Caraça mantinha seus esforços para desenvolver estratégias de permanência na escola para a elite dirigente, pois seriam eles que guiariam a mão de ferro do Estado brasileiro nos anos seguintes.

O Brasil de 1930, esteve protagonizado pelos Patronatos Agrícolas, a exemplo de Pindobal, que são as instituições que formariam uma classe obediente, aqueles formados por instituições a exemplo do Caraça. As distinções desses Brasis que discutimos se configuraram nos papéis sociais de cada classe, os quais seriam resguardados a partir dessas duas concepções: a manutenção do poder e a configuração entre o dirigente e o subalterno.

\section{Conclusão}

Partindo deste cenário, articular elementos narrativos sobre uma instituição local, em diálogo com a concepção de Ensino Agrícola moralizante para a infância e adolescência desvalida, não é uma tarefa fácil, pois as armadilhas que encontramos são inúmeras, passando pelo próprio período estudado - 1930 -, um tempo que não nos pertence, mas que está carregado nas páginas da impressa como um período repleto de conflitos sociais e, especificamente para nós, marcado pela criação de Pindobal.

Pindobal carrega consigo elementos de uma instituição de ensino agrícola e, ao mesmo tempo, de instituição correcional, destinada a corrigir possíveis desvios de condutas, endireitando uma infância e adolescência que serão responsáveis por construir o progresso da nação brasileira com suas próprias mãos.

Portanto, Pindobal é um exemplo de inúmeras instituições que agem em conformidade com as demandas dos setores dominantes, incutam na formação da criança e do adolescente uma ideologia da redenção através do trabalho, e nós, pesquisadores e pesquisadoras de nosso tempo, precisamos estar atentos a essas experiências. Acreditamos que este artigo poderá ser útil para aqueles e aquelas que estão debruçados em entender as instituições profissionais de ensino agrícola, entendendo que precisamos desvelar as suas intenções, de maneira crítica, para que possamos superar todo e qualquer dano causado à infância e à adolescência pobre ao longo das décadas. Este trabalho é um recorte da dissertação que está em fase de 
andamento, esperamos com a análise das fontes obtidas contribuir para a historiografia paraibana e para o desvelar de práticas educativas que são forjadas para determinadas classes sociais, como vimos anteriormente.

\section{Referências}

A Parahyba sob um regimen de trabalho e de progresso: Iniciativas e realizações do actual governo vizinho do Estado - Protecção e assistência à lavoura - Os serviços de abastecimento d'água à Campina Grande (1936). Diário de Pernambuco, Recife, n. 264, http://memoria.bn.br/docreader/D ocReader.aspx ?bib=0 29 033_11\&pagfis=21805.

Andrade, M. G. de. (2000). A educação exilada: Colégio do Caraça. Autêntica.

Barbosa, M. (2007). História cultural da imprensa: Brasil, 1900-2000. Mauad X Editora.

Bogdan, R. C. \& Biklen, S. K. (1999). Investigação Qualitativa em Educação: Uma introdução à teoria e aos métodos. Tradução de Maria João Avarez, Sara Bahia dos Santos e Telmo Mourinho Baptista. Porto Editora.

Correa, M. (2016). A cidade de menores: uma utopia dos anos 30. In: Freitas, Marcos Cezar de (Org). História Social da infância no Brasil. Cortez, 143-164.

Costa, S. (1941). A Escola Rural. Serviço Gráfico do IBGE.

Ginzburg, C. (1989). Mitos, emblemas, sinais: morfologia e história. Trad. Federico Carotti. Companhia das Letras.

Levi, G. (1992) Sobre a micro-história. In: Burke, P. (Org). A Escrita da História: novas perspectivas. São Paulo: Editora da Universidade Estadual Paulista, p.133-162.

Flick, U. (2009) Introdução à pesquisa qualitativa. (3a ed.), Artmed.

Mendonça, S. R. de. (2007). Conflitos intraestatais e política de educação agrícola no Brasil (1930-1950). Revista Tempos Históricos, 10.

Mendonça, S. R. de. (2016). Estado e Educação rural no Brasil: Balanço historiográfico e visão crítica. Entre o local e o global, Anais do XVII Encontro de História da Anpuh-Rio.

Mendonça, S. R. de. (2013). Estado e políticas agrícolas na historiografia brasileira (1930 - 1964). XXVII Simpósio Nacional de História: Conhecimento histórico e diálogo social, Natal.

Mendonça, S. R. de. (1996). Estado, Violência Simbólica e Metaforização da Cidadania. Tempo.

Moraes, C. S. V. (2000). A normatização da pobreza: crianças abandonadas e crianças infratoras. Revista Brasileira de Educação, ANPED.

Nascimento, A. P. (2016). Trabalhadores Negros e o "Paradigma da ausência": contribuições à História Social do Trabalho no Brasil. Estudos Históricos. 29, $607-626$

Nascimento, G. A. do, Machado, C. J. S \& Almeida, A. R. de (2020). O ensino útil para os Menores Transviados: o caso de Pindobal na Paraíba do século XX. Research, Society and Development, 9(8).

Nascimento, G. A. do, Machado, C. J. S. \& Almeida, A. R. de. (2021) Escritos e representações de Jandira Pinto: a reformuladora de Pindobal na Paraíba do século XX. Rev. Pemo, 3, e313816.

O Aprendizado agrícola que o governo do Estado vae instalar na fazenda de Pindobal, em Mamanguape, será dirigido pelo professor Sizenando Costa. (1930) O Município, Acre, Ed. 00772.

Passetti, E. (2004). Criança Carentes e políticas públicas. In: Priori, M. D. (Org). História das Crianças no Brasil. (4a ed.), Contexto.

Pelos Estados: Parahyba. (1930). O Município, Acre, Ed. 00767.

Prando, C. C. M. (2014). A contravenção Penal de vadiagem no Rio de Janeiro (1900-1940): Legalismo e prevencionismo nas decisões penais. In: História do Direito I: XXIII Congresso Nacional Conpedi/UFPB. Ed. Conpedi

Rizzini, I. (2011). Meninos desvalidos e menores transviados: a trajetória da assistência pública até a Era Vargas. In: Rizzini, I., Pilotti, F. (Org). A arte de governar crianças: A história das políticas sociais, da legislação e da assistência a infância no Brasil. (3a ed.), Cortez, 225-286.

Rizzini, I \& Celestino, S. (2016). A cultura da institucionalização e a intensificação das práticas de confinamento de crianças e adolescentes sob a égide da FUNABEM. In: Freitas, M. C. (Org). História Social da infância no Brasil. Cortez, p. 229-250.

Santos, M. A. C. dos. (2004). Criança e Criminalidade no início do século. In: Priore, M. D. (Org). História das Crianças no Brasil. (4a ed.), Contexto.

Uma Bella Fundação em João Pessoa na Parahyba. (1931). A Noite Illustrada. (88)

Vainfãs, R. (2002). Os Protagonistas Anônimos da História: Micro-História. Campus. 